\title{
Estimation of Particle Mass Flow Rate in Free Jet Using In-Flight Particle Diagnostics in Plasma Spraying
}

\author{
K. Bobzin ${ }^{1}$ W. Wietheger ${ }^{1}$ M. A. Knoch ${ }^{1} \cdot$ S. R. Dokhanchi ${ }^{1}$
}

Submitted: 14 November 2019/in revised form: 14 March 2020/Published online: 28 April 2020

(C) The Author(s) 2020

\begin{abstract}
In-flight particle diagnostics have enhanced our understanding of thermal spraying and improved coating reproducibility. However, no methodology to verify the measured in-flight particle properties has been proposed in the literature yet. This methodology requires describing the entire free jet from accurate measured values. This study deals with a novel method to verify the measured in-flight particle sizes and velocities by estimating the particle mass flow rate (PMFR) in the free jet. To this end, the entire free jet cross section was divided into several non-overlapping focal planes, and the size and velocity of the in-flight particles were measured by optical diagnostics at these focal planes. The PMFR of the powder feeder was used as a reference to validate the determined PMFR in the free jet. The results showed a good agreement with the PMFR of the powder feeder and could be replicated with different feedstock powders, demonstrating the capability of the developed method. Furthermore, the determined PMFR distribution in the entire free jet, referred to as digital footprint, agreed well with the height of the experimental footprints of the spray jet on a substrate. Consequently, it can be concluded that the spatial PMFR distribution was also properly measured.
\end{abstract}

Keywords atmospheric plasma spraying - deposition pattern - in-flight particle diagnostics - particle mass flow rate $\cdot$ spray footprint

\footnotetext{
S. R. Dokhanchi

dokhanchi@iot.rwth-aachen.de

1 Surface Engineering Institute (IOT), RWTH Aachen University, Aachen, Germany
}

\section{Introduction}

Atmospheric plasma spraying is the most flexible of all thermal spraying technologies, since it can be used in combination with a wide variety of feedstock materials, which can be injected radially or axially in the plasma jet (Ref 1). In plasma spraying with a radial injection system, not all of the injected particles penetrate in the plasma jet. Due to insufficient particle momentum relative to the momentum of the plasma jet at the point of injection, a portion of particles bypass or bounce off from the free jet. The carrier gas flow, the particle size distribution of the feedstock material, the injector nozzle diameter and its position as well as the plasma properties control the dispersion of the particles in the plasma jet (Ref 2). The feedstock particles, after penetrating in the free jet, are heated and accelerated toward a prepared substrate. The impact of subsequently approaching particles build-up a coating (Ref 3 ). The temperature and velocity of the particles vary significantly in the plasma jet, depending whether the particles are in the hot core of the jet or in its relatively cold outer part. Due to this temperature and velocity difference in the free jet, the deposition behavior of the particles on the substrate depends on their individual trajectory (Ref 4). The cumulative deposition profile of the impacted particles, known as spray footprint or spray pattern, is helpful to find a compromise between deposition efficiency and process variables, such as powder flow rate, electric current and carrier gas flow (Ref 5). A high deposition efficiency is desirable in many applications for economical reasons.

The evolution of sensors in thermal spraying for particle in-flight diagnostic measurements has progressed considerably in recent years. Particle diagnostic systems have broadened our understanding of the spraying process and 
improved the reproducibility of the coatings. However, there are still issues that need to be addressed. The relationship between input process parameters and coating characteristics is described by the in-flight particle properties (Ref 6). Therefore, it is of great importance to gain precise and reliable knowledge regarding the particle behavior in the free jet. Yet, there has not been a methodology to verify the in-flight diagnostic measurements. The reason for this is the incomplete detection of the free jet, which makes the verification of the measured data more difficult. In principle, the particle diagnostic systems focus on one point or one focal plane and therefore, they can only partially capture the free jet. This point or plane is usually chosen in view of the maximum concentration of the particles, and then a rotationally symmetrical free jet is assumed. This assumption is generally not correct due to incessant plasma fluctuations. In addition, given the dynamic range and signal-to-noise ratio of the diagnostic sensors, only particles within a certain measurable range are detected (Ref 7). Thus, particle diagnostic systems show deficits in measured data and do not allow a holistic recording of the free jet. The detection of the entire free jet as well as the verification of the diagnostic measurements represents a central research need in the field of thermal spraying. Hence, these subjects are addressed in this study. For this purpose, a novel method based on particle diagnostics is introduced to estimate the particle mass flow rate (PMFR) in the free jet. To the best knowledge of the authors, such a method has not been reported in the literature so far. In this approach, the PMFR of the powder feeder is used as a reference to verify the measured data.

In conventional spray processes, there are some particle diagnostic methods and systems such as phase doppler anemometry (PDA), DPV-2000, Accuraspray and HiWatch CS. The latter is employed in this study, and its functional principle is discussed later in detail. In case of the PDA technique, the particle morphology must be spherical, and therefore, it is not possible to measure angular and blocky particles. The DPV-2000 is a well-established diagnostic system, which has a relatively small measurement volume $\left(<1 \mathrm{~mm}^{3}\right)$. The Accuraspray operates based on the ensemble measurement technique, and therefore has a lager measurement volume than the DVP-2000. Ensemble measurement techniques do not attempt to distinguish between individual particles and only give mean values (Ref 8). Consequently, they are not suitable for the PMFR measurement in the entire free jet. The HiWatch system, in addition of having the capability to observe a single particle, has a relatively large measurement volume $(6.5 \mathrm{~mm} \times 9 \mathrm{~mm} \times 2 \mathrm{~mm})$. Therefore, the HiWatch has the advantage to capture the entire free jet with smaller number of individual measurements, while retaining the option to analyze individual particles. Theoretically, it is possible to use other diagnostic systems for the PMFR measurement, if they deliver the size and velocity of the individual particles simultaneously, e.g., DPV-2000.

An in situ measurement of the PMFR in the free jet is a technically challenging issue, which can be increasingly significant to attain efficient utilization of the feedstock powder and to reduce overspray. The main challenge is that capturing the average particle properties at the free jet center would not be sufficient to measure the PMFR. Thereby, it is necessary to capture the entire free jet to attain a good estimation of the PMFR based on the absolute values of the particle properties existing in the free jet. Although extensive research has been devoted to study the effect of different spraying parameters on the particle inflight properties, such as particle size, surface temperature and velocity (Ref 9-16), measuring the portion of particles existing in the entire free jet has not been addressed yet. Wiederkehr et al. (Ref 17) presented an approach to reconstruct spray footprints computationally by obtaining a mass flow function from the 3D coating profiles of experimental footprints. However, this approach is not suited for real-time process control.

In the field of pneumatic conveying, different techniques have been developed to measure the mass flow rate of pulverized solids in pneumatic conveying pipelines (Ref 18). Ding Song et al. (Ref 19) proposed a digital imageprocessing-based method to measure the mass flow rate of the pneumatic conveyed particles in a gas/solid two-phase flow. However, measurement of the PMFR in a plasma jet is more challenging due to much higher particle velocities and different process conditions.

\section{Experimental Setup}

To determine the in-flight PMFR, the entire free jet cross section is divided into several non-overlapping focal planes. Optical particle diagnostics have been carried out to measure the size and velocity of the in-flight particles at these focal planes. A mathematical model is proposed to derive the PMFR in the free jet based on the measured inflight particle sizes and velocities. The PMFR of the powder feeder is utilized as a reference to validate the diagnostic measurements. Subsequently, the PMFR distributions at the entire free jet are compared to the experimentally generated footprints. The PMFR distribution at the entire free jet will be referred to simply as "digital footprint" for the remainder of this paper. 


\subsection{Spray Parameters and Materials}

Experiments were carried out with two plasma generators: the single-cathode F4MB-XL (Oerlikon Metco, Kelsterbach, Germany) and the three-cathode TriplexPro ${ }^{\mathrm{TM}}-210$ (Sulzer Metco, Kelsterbach, Germany). The plasma torches were mounted on a six-axis robot (KUKA Roboter, Augsburg, Germany). The APS system was equipped with an external powder feeder with a transverse particle injection system relative to the horizontal torch axis. A conventional $\varnothing=2 \mathrm{~mm}$ diameter injector was used. Diagnostic experiments were conducted with two commercial feedstock materials: alumina (AMDRY 6062, Oerlikon Metco, Kelsterbach, Germany) and aluminum bronze (Metco 51NS, Oerlikon Metco, Kelsterbach, Germany). The volume-based particle size distributions as well as other properties of the feedstock powders used in this study are given in Table 1 . The powders were chosen based on different particle sizes and morphologies. The size distribution of the particles was ascertained by the particle analyzer Morphologi G2 (Malvern Instruments, Herrenberg, Germany). The spray parameters with regard to the plasma torches and feedstock powders are listed in Table 2 .

\subsection{Particle Diagnostics}

Particle diagnostic measurements were performed using the particle diagnostic system HiWatch CS (Oseir Ltd., Tampere, Finland). The output data of this diagnostic tool are, among others, the size, velocity and position of the particles. The device package consists of a pre-aligned assembly of a CCD camera and a pulsed diode laser head with a power of $50 \mathrm{~W}$. The operation principle of the HiWatch system is based on stroboscopic image analysis, where the particles on certain cross section of the free jet are recorded using triple-exposure imaging, see Fig. 1. The measuring area with standard optics is $6.5 \mathrm{~mm}$ in the spray direction and $9 \mathrm{~mm}$ perpendicular to the spray direction, see Fig. 2. The depth of field of the camera lens in $z$ direction is about $2 \mathrm{~mm}$. The object space resolution is

Table 1 Properties of the feedstock powders used in this study

\begin{tabular}{lll}
\hline Property & \multicolumn{1}{c}{$\mathrm{Al}_{2} \mathrm{O}_{3}$} & $\mathrm{Cu} \mathrm{10 \textrm {Al }}$ \\
\hline$D[v, 0.05], \mu \mathrm{m}$ & 17.6 & 28.58 \\
$D[v, 0.5], \mu \mathrm{m}$ & 31.85 & 75.06 \\
$D[v, 0.95], \mu \mathrm{m}$ & 50.3 & 125.7 \\
Density, g/cm ${ }^{3}$ & 3.98 & 7.57 \\
Manufacture & Fused and crushed & Gas atomized \\
Morphology & Angular/blocky & Spheroidal \\
\hline
\end{tabular}

$6.8 \mu \mathrm{m} /$ pixel. Particle sizes are calculated by the average reflection intensity of the multiple images of a particle. In contrast to the emissivity, the reflectivity of the particles under the applied laser illumination with a wavelength of $\lambda=810 \mathrm{~nm}$ is almost independent of the particle temperature. Thus, the size of both hot and cold particles can be determined. The particle velocities are calculated by the travel distance in the image and the laser pulse time interval. Depending on the measurement location in the free jet, the laser pulse interval was set in the range of 0.3$25 \mu$ s and the pulse duration in the range of $0.16-0.5 \mu$ s. The laser settings for the individual measurements were adjusted using the live view option to capture as many particle triplets as possible while avoiding overlapping of these triplets.

\subsection{PMFR of the Powder Feeder}

The PMFR of the powder feeder is used as a reference to validate the determined PMFR in the free jet. This was determined by capturing and weighing the amount of powder fed into a closed container within a certain time. The measurements were performed three times. The argon carrier gas for the $\mathrm{Al}_{2} \mathrm{O}_{3}$ powder was set to 5.5 SLPM and for the $\mathrm{Cu} 10 \mathrm{Al}$ powder to 3.5 SLPM. In each case, the same carrier gas flow was used as in the diagnostic experiments. The average PMFR of the powder feeder for the both feedstock powders is shown in Fig. 3 against different metering disk settings. As shown in Fig. 3, the PMFR increases almost linearly with the increase in the metering disk setting.

\subsection{Particle Size Normalization}

The particle sizes measured by the HiWatch showed a deviation compared to the morphology results. One possible explanation could be the background subtraction algorithm, which slightly alters the particle shapes in the recorded images. It should be mentioned that the object space resolution of the HiWatch is not a limitation for the particle detectability. The minimum measurable particle size by the HiWatch is $5 \mu \mathrm{m}$. However, due to imaging system non-idealities, the particles appear larger than they are and therefore, their size will be overestimated, but the position and velocity measurements are not affected by this. Therefore, to avoid overestimating the PMFR, the measured particle sizes in the entire free jet for the both feedstock powders were normalized based on the morphology results. Thereby, a linear regression was used to normalize the detected particle sizes based on the $D[v$, $0.05]$ and $D[v, 0.95]$ of the particles stated in Table 1 . Figure 4 shows the volume-based particle size distribution exemplarily for the $\mathrm{Al}_{2} \mathrm{O}_{3}$ powder using the particle size 
Table 2 Spray parameters used for particle diagnostic experiments

\begin{tabular}{lccc}
\hline Parameter & Single-cathode gun & Single-cathode gun & Three-cathode gun \\
\hline Feedstock material & $\mathrm{Al}_{2} \mathrm{O}_{3}$ & $\mathrm{Cu} \mathrm{10Al}$ & $\mathrm{Al}_{2} \mathrm{O}_{3}$ \\
Current, A & 600 & 500 & 500 \\
Input power, kW & 35.6 & 25.5 & 48.4 \\
Argon, slpm & 42 & 50 & 60 \\
Hydrogen, slpm & 9 & 2 & $\ldots$ \\
Carrier gas, slpm & 5.5 & 3.5 & 5.5 \\
Nozzle diameter, mm & 6 & 6 & 9 \\
\hline
\end{tabular}

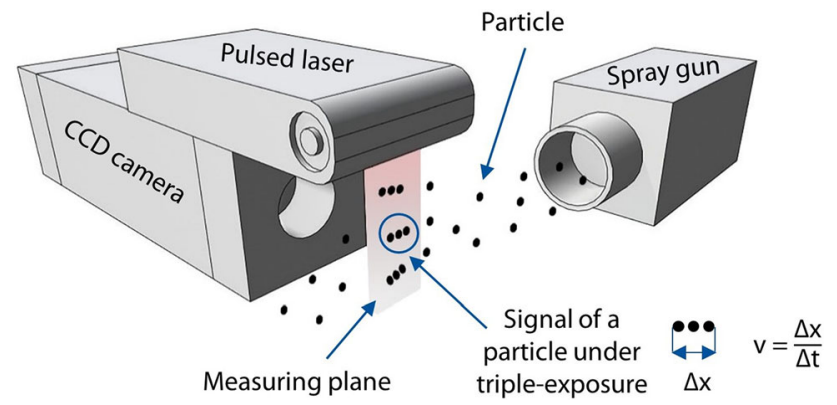

Fig. 1 Schematic configuration of the particle diagnostic system HiWatch

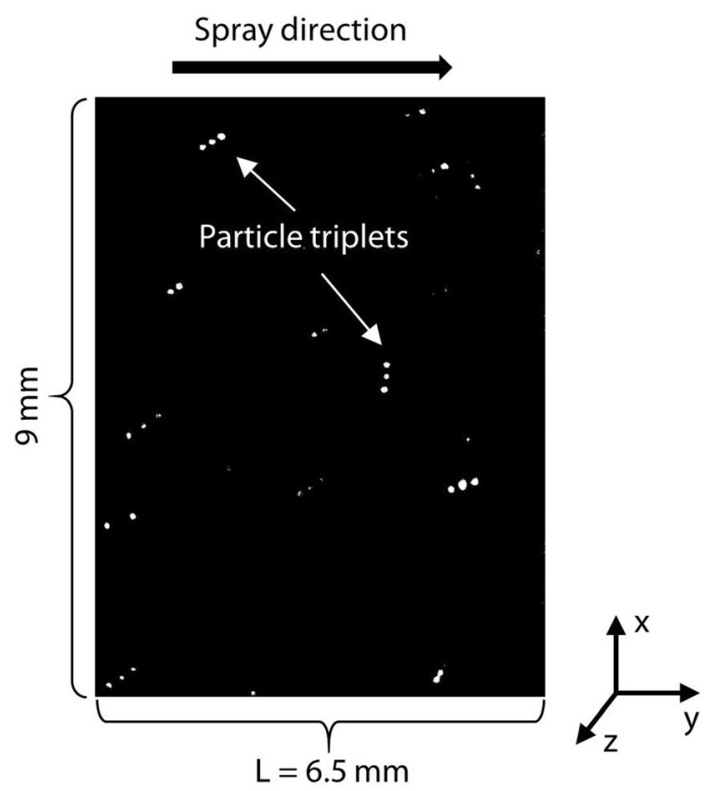

Fig. 2 Measurement image of the HiWatch at a focal plane of the free jet

analyzer as well as the diagnostic system HiWatch before and after normalization. The particle size distribution after normalization shows a good agreement with the morphology distribution. With respect to this size normalization and the conservation of mass, the particle density in room temperature can be assumed for the in-flight particles as well.

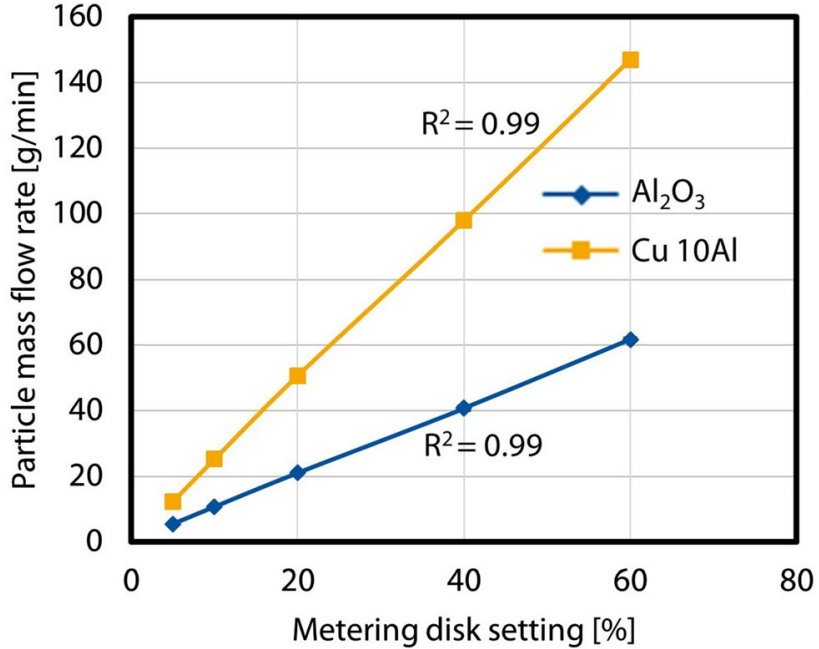

Fig. 3 Average PMFR of the powder feeder for the two feedstock powders against different metering disk settings

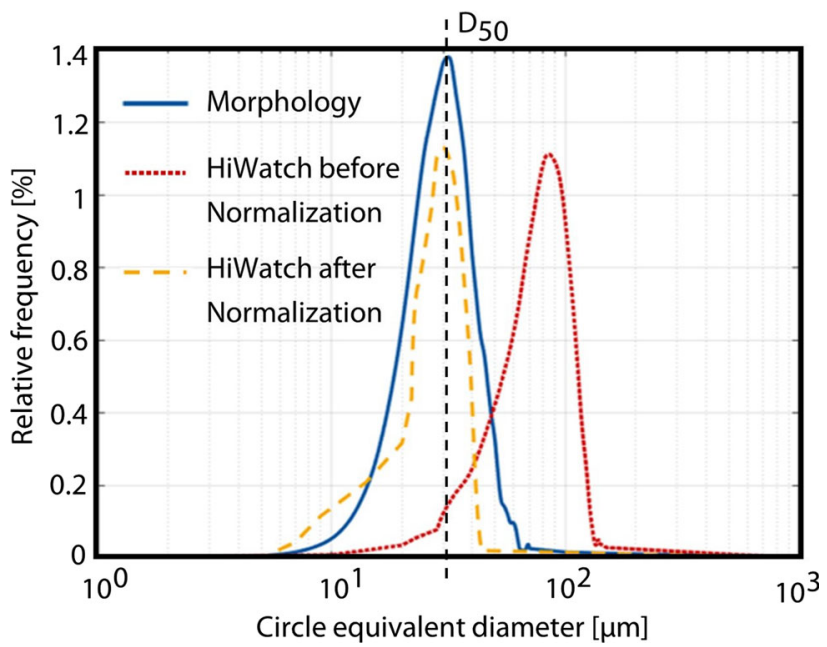

Fig. 4 Comparison of exemplarily determined particle sizes before and after normalization with the morphology results for $\mathrm{Al}_{2} \mathrm{O}_{3}$ feedstock powder

\subsection{PMFR Measuring Principle in Free Jet}

Experimental footprints were produced at a stand-off distance of $100 \mathrm{~mm}$ to determine the section of the free jet in 
which most particles are located. The point with maximum particle intensity was then considered as the reference point for the particle diagnostic experiments. Prior to generating the footprints, all substrates were roughened using an injector blasting system. The height profiles of the applied experimental footprints were measured using a confocal laser-scanning microscope (VK-X210 Keyence, Neu-Isenburg, Germany). Afterward, these profiles are compared with the digital footprints.

The PMFR of a focal plane from a HiWatch image was calculated based on the following equation:

$\dot{m}=\sum_{i=1}^{n} \frac{\rho \frac{4}{3} \pi\left(\frac{D_{i}}{2}\right)^{3} v_{i}}{L}$

where $\dot{m}, \rho, D, v, n$ and $L$ are PMFR, particle density, particle diameter, particle velocity, number of particles in an image and measuring length of the camera in the spray direction, respectively. At each focal plane, 250 images were captured and the PMFR of a focal plane corresponds to the average PMFR of all images captured at that focal plane. Figure 5 shows the measured area of the free jet schematically. The free jet cross section was divided into 15 focal planes in $z$ direction and three stages in $x$ direction, see Fig. 5. The particle diagnostic measurements and experimental footprints were performed at a spray distance of $100 \mathrm{~mm}$. The center of the middle stage corresponds to the point with maximum particle intensity, which was determined by experimental footprints. At each stage, 15 individual diagnostic measurements were carried out by moving the robot at an increment of $2 \mathrm{~mm}$ in $z$ direction, which equals the depth of field of the CCD camera. Therefore, an area of $9 \mathrm{~mm} \times 2 \mathrm{~mm}$ in $x z$ plane was covered by each individual measurement. Subsequently, the PMFR values corresponding to each individual measurement were calculated based on Eq 1. Finally, the PMFR of the entire measuring area was determined by summation of the obtained PMFR values of the three stages. In this approach, no symmetric distribution of PMFR in the free jet was assumed. It must be pointed out that, as another approach, the PMFR of the focal plane with maximum particle intensity was also integrated rotationally symmetric over the entire free jet. The results showed an overestimation in the PMFR relative to the PMFR of the powder feeder, which makes the symmetric assumption impermissible.

To visualize the spatial PMFR distribution, digital footprints were created based on the determined PMFRs of the all individual measurements. For this purpose, the particle positions in each focal plane were taken into account. The HiWatch system delivers the position of the center of the captured particle triplets in a measurement image, with reference to the upper and left edge of the image. Figure 6 illustrates the covered free jet cross section by a single measurement together with particle positions schematically. In Fig. 6, the particles are sprayed in $y$ direction and the HiWatch captures the particles in $z$ direction. The $x z$ plane was divided into several sections along the $x$-axis. The PMFR for each section was projected onto the $x z$ plane to create a digital footprint. These digital footprints are compared to the previously produced experimental footprints to validate the results.

\subsection{PMFR Calibration}

Since the particle diagnostic systems are not fully capable to detect all the existing particles in the entire free jet, a calibration of the captured PMFR is necessary. The PMFR directly at the outlet of the injection nozzle was measured to calibrate the determined PMFR in the free jet, see Fig. 7. This allows to capture all injected particles at one focal plane. In this approach, the PMFR at the injection nozzle outlet was calculated and compared with the corresponding PMFR of the powder feeder for different metering disk settings. The PMFR of the $\mathrm{Al}_{2} \mathrm{O}_{3}$ feedstock material at the injector outlet and the corresponding PMFR of the powder feeder are given in Table 3 for different metering disk settings. It can be seen that up to a metering disk setting of $5 \%$, almost a constant proportion of the PMFR was
Fig. 5 Schematic illustration of the measured area of the free jet by diagnostic experiments

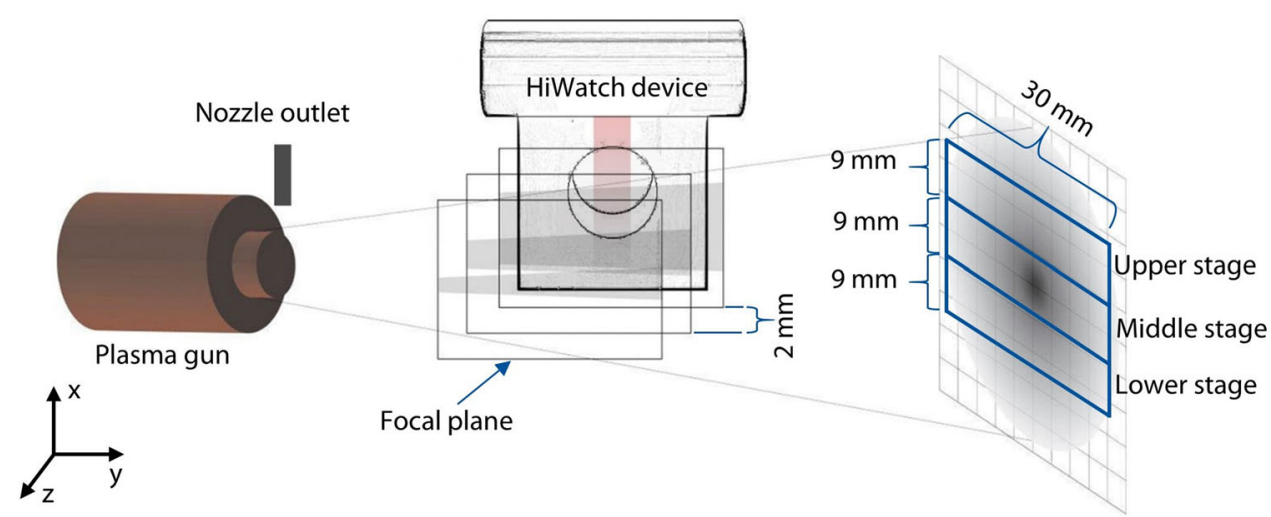




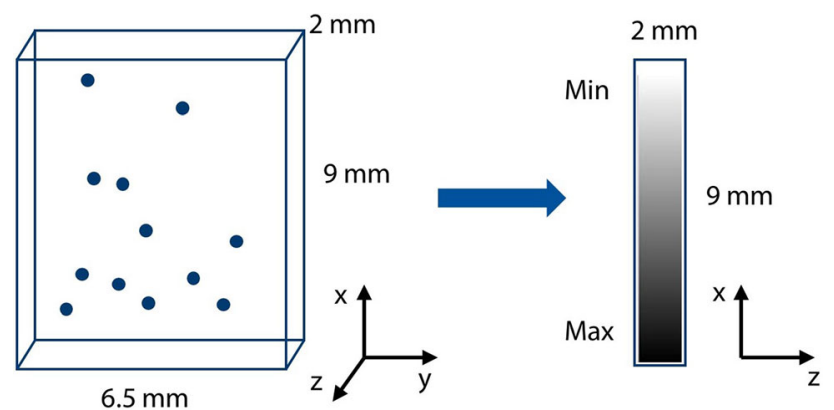

Fig. 6 Schematic illustration of an individual measurement in terms of considering the particle positions for precise visualization of the digital footprint

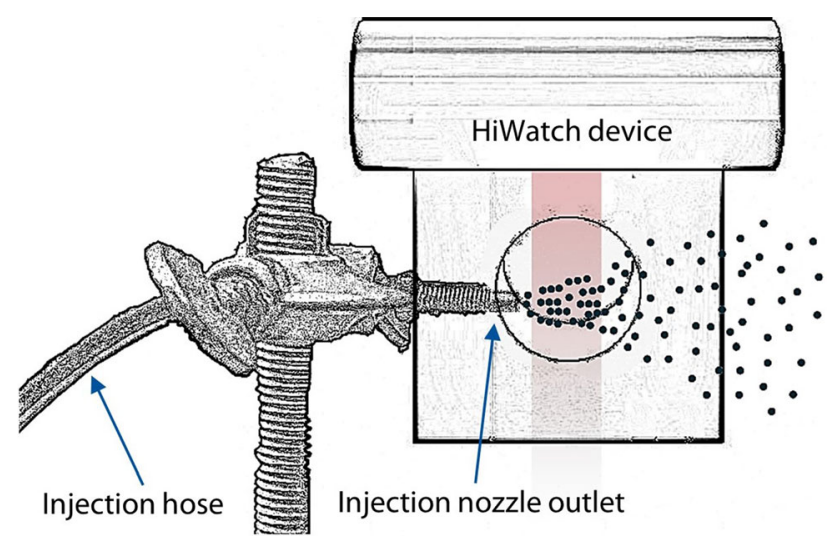

Fig. 7 Schematic illustration of capturing the particles directly at the outlet of the injection nozzle

obtained. With higher metering disk settings, due to a dense crowd of particles at the focal plane, the measured values are not reliable. The HiWatch images at the injector outlet are shown in Fig. 8. $\Psi_{\mathrm{i}}$ represents the proportion of the detected PMFR relative to the PMFR of the powder feeder, and MD is the metering disk setting in percentage. It is evident that $\Psi_{\mathrm{i}}$ has been greatly decreased in the case of $10 \%$ and $20 \%$ of MD, since the particle triplets overlap with each other, and therefore the HiWatch cannot reliably evaluate the measured images of the overlapped particles.
On the contrary, such a high particle concentration is not expected at a focal plane in the free jet.

The proportion of the determined PMFR at the injector outlet $\left(\Psi_{\mathrm{i}}\right)$ is plotted against the metering disk setting in Fig. 9. Up to a metering disk setting of $5 \%$, almost $47 \%$ of the PMFR of the powder feeder could be obtained. Thus, a factor of roughly 2.1 should be taken into account to calibrate the PMFR in the free jet. This calibration factor determined at the nozzle outlet is validated afterward by measuring the PMFR in the free jet in case of different spray powders and plasma generators. The results reveal no dependencies on particle size and material. However, this calibration factor may vary for other diagnostic systems.

\section{Results and Discussion}

The described method was implemented in the programming environment MATLAB, to calculate the PMFR from the individual measurements and visualize digital footprints based on the PMFR distributions in the free jet. In the following, the results from different plasma guns and feedstock materials are presented and discussed.

\subsection{Single-Cathode Plasma Torch}

In the case of the single-cathode plasma generator, particle diagnostic measurements were carried out for the $\mathrm{Al}_{2} \mathrm{O}_{3}$ and $\mathrm{Cu} 10 \mathrm{Al}$ feedstock powders with different metering disk settings of the powder feeder. The determined PMFR in the free jet and the corresponding PMFR of the powder feeder are given in Table 4. The proportion of the detected PMFR in the free jet $\left(\Psi_{\mathrm{f}}\right)$ agrees well with the calibration factor determined directly at the injector outlet which was calculated to be $\Psi_{\mathrm{i}}=0.47$. Therefore, the PMFR in the free jet can be estimated with a deviation of less than 5\% relative to the PMFR of the powder feeder. A slight increase in $\Psi_{\mathrm{f}}$ has been observed for the $\mathrm{Cu} 10 \mathrm{Al}$ feedstock powder. This can be explained by the fact that the particle

Table 3 Results of the determined PMFR directly at the injector outlet

\begin{tabular}{lcccc}
\hline Metering disk, $\%$ & Number of particles in 250 images & \multicolumn{2}{c}{ PMFR, g/min } & Proportion of the detected PMFR ( $\left.\Psi_{\mathrm{i}}\right)$ \\
\cline { 3 - 4 } & & Injector outlet & Powder feeder & 0.52 \\
\hline 0.5 & 345 & 0.28 & 0.53 & 0.46 \\
1 & 762 & 0.50 & 1.08 & 0.45 \\
2 & 1502 & 0.95 & 2.12 & 0.44 \\
5 & 3575 & 2.46 & 5.5 & 0.23 \\
10 & 3088 & 2.42 & 10.75 & 0.06 \\
\hline
\end{tabular}


Fig. 8 HiWatch images

captured directly at the outlet of the injection nozzle
MD $=$ Metering disk $\mid \Psi_{\mathrm{i}}=$ Proportional PMFR detected at the injector
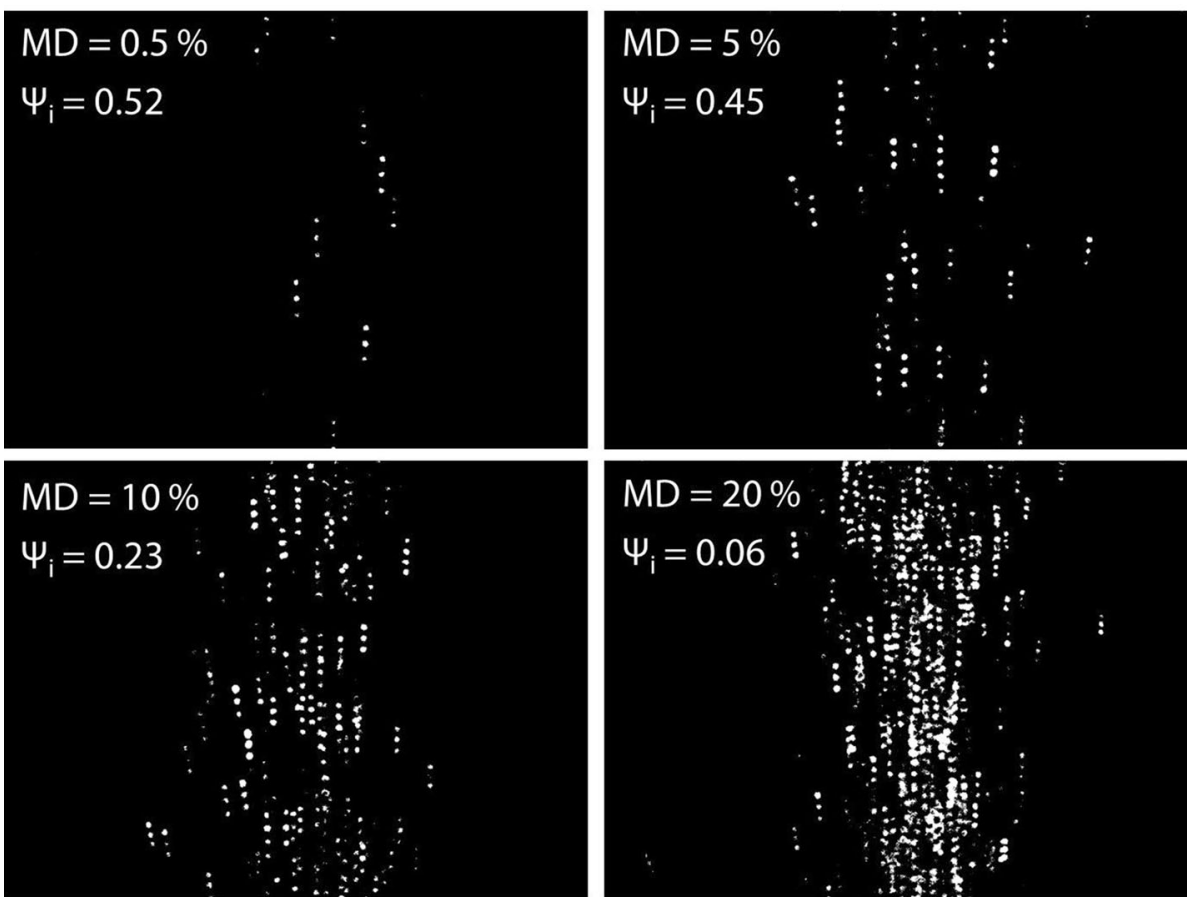

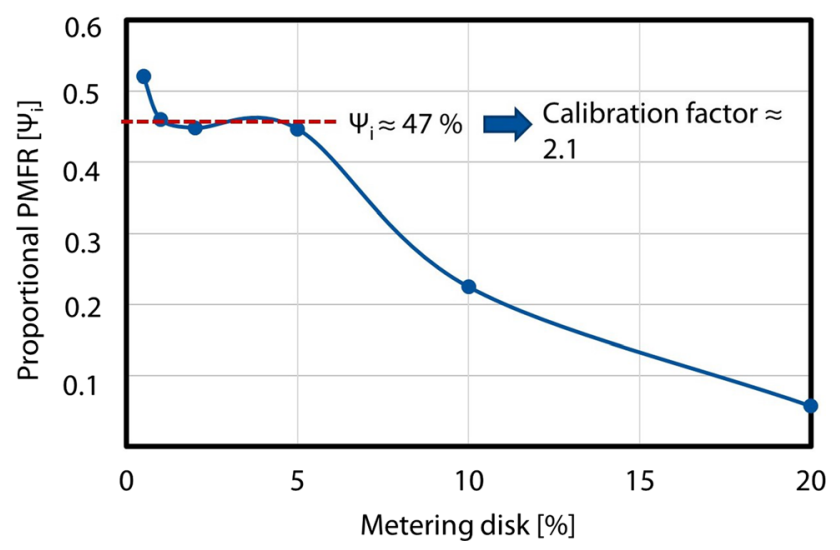

Fig. 9 Proportional PMFR detected at the injection nozzle outlet against different metering disk settings diagnostic device can calculate the size of a spherical particle more precisely, since the calculation error for determining the circle equivalent diameter is smaller for a regularly shaped particle. In addition, the HiWatch can determine large particle sizes from a diameter of $d>50 \mu \mathrm{m}$ more accurately. Furthermore, the $\mathrm{Cu} 10 \mathrm{Al}$ powder particles possess greater momentum due to their larger particle sizes. This leads to less overspray outside the measuring area in comparison with the $\mathrm{Al}_{2} \mathrm{O}_{3}$ particles.

Figure 10 shows (a) the experimentally generated footprint under the laser-scanning microscope and (b) the digital footprint based on the PMFR distribution in the free jet for the $\mathrm{Al}_{2} \mathrm{O}_{3}$ feedstock powder. The profile of the digital footprint closely matches with the experimental footprint. Nonetheless, the higher amounts of PMFR on the

Table 4 Results of the PMFR determination for different feedstock powders and metering disk settings using single-cathode torch

\begin{tabular}{lcccc}
\hline $\begin{array}{c}\text { Feedstock } \\
\text { powder }\end{array}$ & $\begin{array}{c}\text { Metering disk setting, } \\
\%\end{array}$ & $\begin{array}{c}\text { PMFR in free jet, } \\
\text { g/min }\end{array}$ & $\begin{array}{c}\text { Corresponding PMFR of the powder feeder, } \\
\text { g/min }\end{array}$ & $\begin{array}{c}\text { Proportional PMFR in free jet } \\
\left(\Psi_{\mathrm{f}}\right)\end{array}$ \\
\hline $\mathrm{Al}_{2} \mathrm{O}_{3}$ & 10 & 5.2 & 10.75 & 0.48 \\
$\mathrm{Cu} \mathrm{10Al}$ & 20 & 25.2 & 50.66 & 0.49 \\
\hline
\end{tabular}


Fig. 10 (a) Experimental footprint profile under laserscanning microscope and (b) digital footprint using single-cathode gun and $\mathrm{Al}_{2} \mathrm{O}_{3}$ feedstock powder
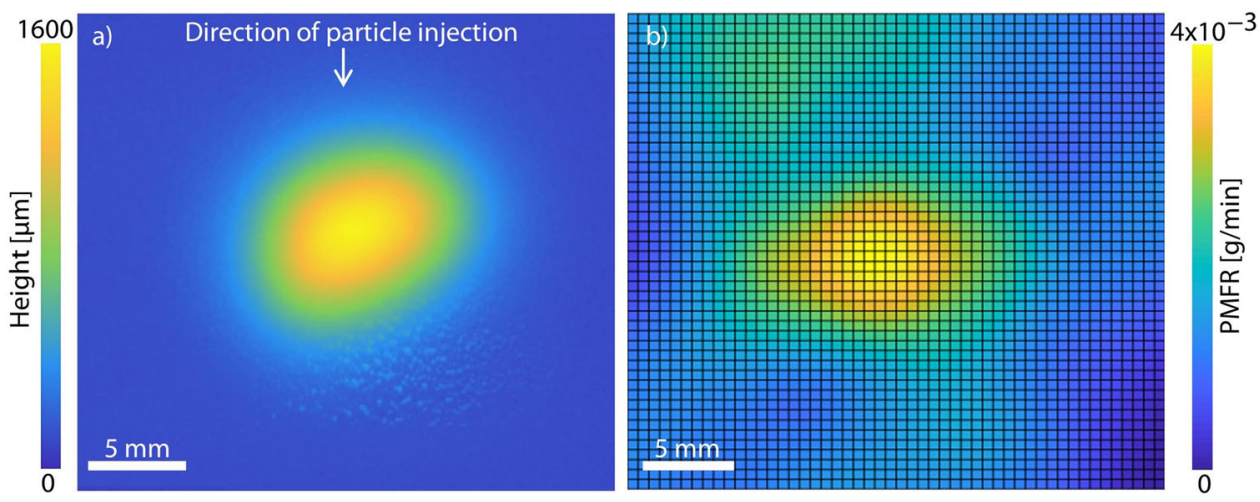

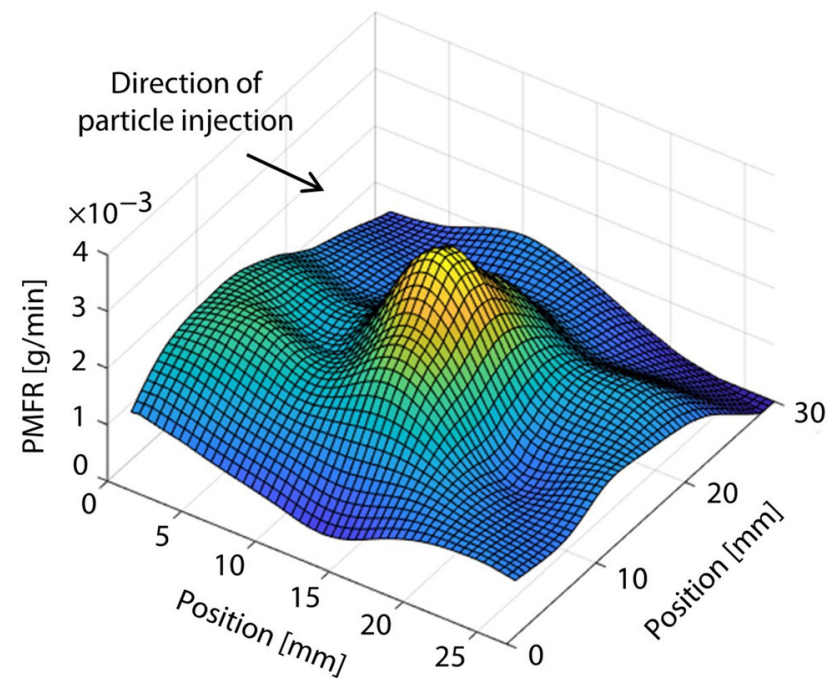

Fig. 11 Three-dimensional profile of the digital footprint using single-cathode gun and $\mathrm{Al}_{2} \mathrm{O}_{3}$ feedstock powder

boundaries of the digital footprint represent the in-flight particles which have not been deposited on the substrate. The presence of such unmolten or partially molten in-flight particles is also evident on the periphery of the 3D digital footprint, shown in Fig. 11. The dense center of the footprint is attributed to the particles with the highest melting ratio. Moving radially out from the center, where fewer particles are dispersed, the plasma temperature decreases relatively and therefore, the particles deposit barely on the substrate. From the comparison of the experimental and digital footprints in Fig. 10, it can be concluded that the most important factor, which affects the particle deposition behavior, is its trajectory. This depends whether the particle trajectory lies primarily within the free jet core or outside of it (Ref 20).

The profiles of the experimental and digital footprints for the experiments with the $\mathrm{Cu} 10 \mathrm{Al}$ feedstock powder and use of the single-cathode gun are shown in Fig. 12. An irregular bean-shaped profile can be observed in both footprints. Figure 13 illustrates the digital footprint in 3D. The two peaks in PMFR values can be attributed to the arc motion fluctuations and restrike inside the torch. Considering the design of the single-cathode plasma gun, the attachment of the electric arc root over the inner surface of the anode can change mainly due to the strong plasma gas flow. This is advantageous to the anode lifetime, since the large heat load can be distributed over the gun nozzle (Ref $21)$. On the contrary, changing the position of the anode attachment leads to variations in arc length and therefore, results in arc voltage/power fluctuations (Ref 22). Subsequently, these fluctuations inside the single-cathode torch influence the in-flight particle behavior in the plasma jet. The 3D profile of the digital footprint in Fig. 13 signifies the capability of the developed method to obtain an asymmetrical spray pattern with regard to the plasma fluctuations. Furthermore, fine particles at the outer part of the free jet tend to oxidize more due to the entrained air from the surrounding atmosphere (Ref 23). This leads to the presence of undeposited particles at the footprint periphery, which are also visible in Fig. 13.

\subsection{Three-Cathode Plasma Torch}

Diagnostic experiments were conducted using the threecathode plasma gun with the feedstock material $\mathrm{Al}_{2} \mathrm{O}_{3}$ for a metering disk setting of $10 \%$. In this case, the PMFR was determined to be $5.6 \mathrm{~g} / \mathrm{min}$ which yields to a proportional PMFR of $\Psi_{\mathrm{f}}=0.52$. The results show a minor increase in the proportional PMFR compared to the single-cathode torch.

Experimental and digital footprints resulting from the three-cathode plasma gun are shown in Fig. 14. A nearly symmetric and round-shaped spray pattern is visible in both cases. This can be explained through different construction concepts of the plasma guns. The three-cathode plasma gun utilizes a triple axially symmetrical arc system, which results in the decrease in the local heat load to the 
Fig. 12 (a) Experimental footprint profile under laserscanning microscope and (b) digital footprint using single-cathode gun and $\mathrm{Cu} 10 \mathrm{Al}$ feedstock powder
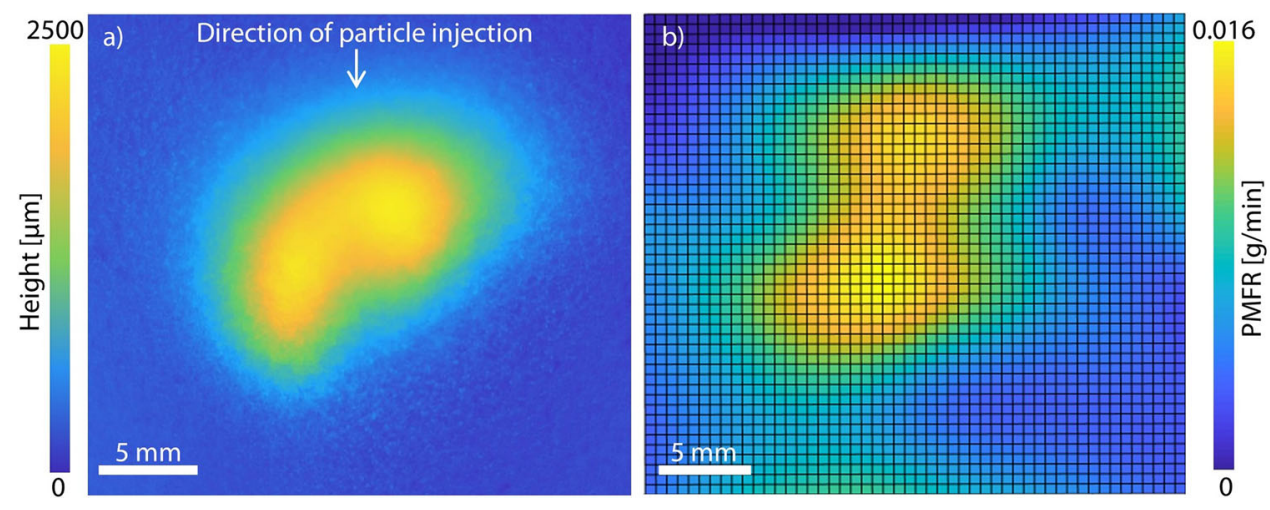

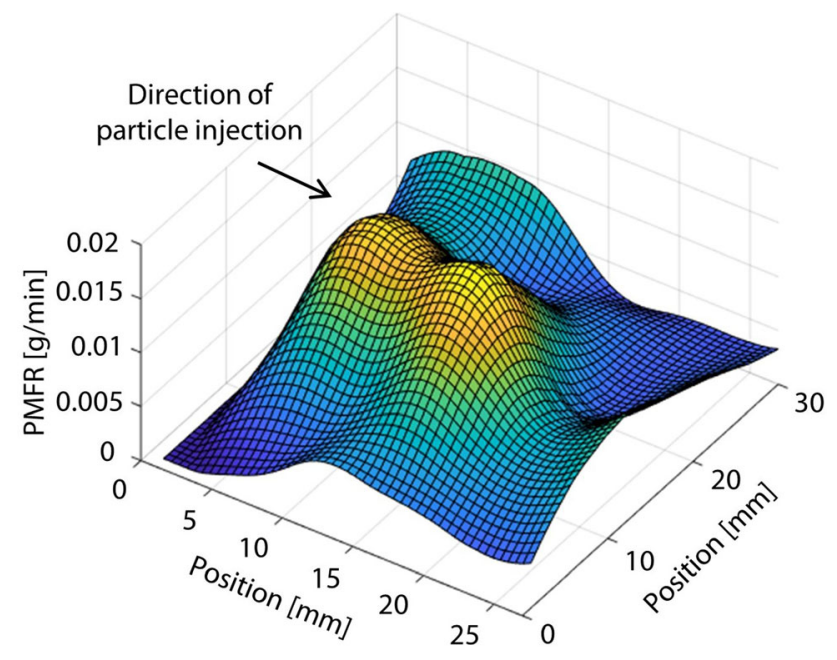

Fig. 13 Three-dimensional profile of the digital footprint using single-cathode gun and $\mathrm{Cu} 10 \mathrm{Al}$ feedstock powder

anode ring (Ref 24). Moreover, it features a relative stable plasma jet due to less fluctuation of the electric arc length inside the torch (Ref 20). This leads to a homogenous heat treatment of the powder particles in the free jet and consequently a uniform deposition pattern. The 3D illustration of the digital footprint is depicted in Fig. 15. The PMFR values at the outer part of the footprint, in contrast to the one with the single-cathode torch, are almost homogenously near zero. This observation demonstrates

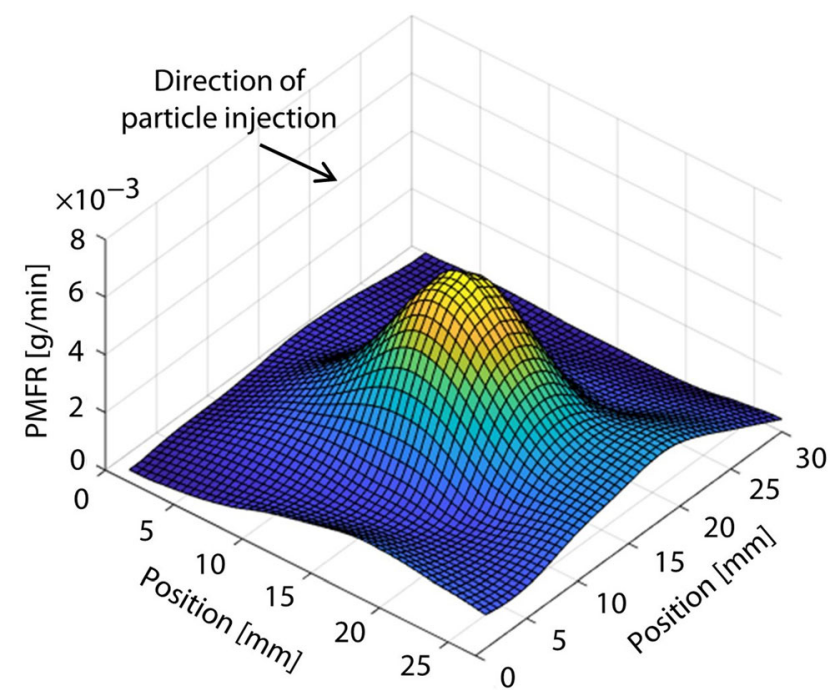

Fig. 15 Three-dimensional profile of the digital footprint using threecathode gun and $\mathrm{Al}_{2} \mathrm{O}_{3}$ feedstock powder

the advantage of the multi-arc plasma chamber geometry with regard to the stability of the plasma jet under the applied process parameters. The cascaded design of the three-cathode plasma gun results in a ring-shaped high viscous flow surrounding the plasma jet that helps the particle trajectories to stay in the high temperature core of the plasma jet (Ref 25). The process parameters, such as electric current and plasma gas flow rate have strong
Fig. 14 (a) Experimental footprint profile under laserscanning microscope and (b) digital footprint using threecathode gun and $\mathrm{Al}_{2} \mathrm{O}_{3}$ feedstock powder
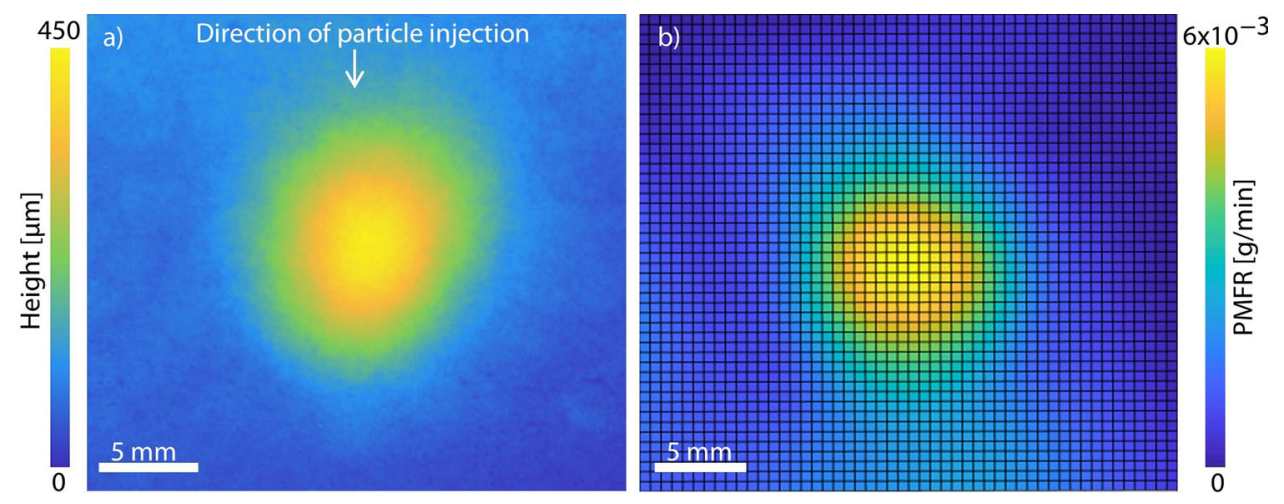
influence on the position and intensity of the surrounding viscous flow (Ref 26). Hence, the multi-arc spray system allows a confining path for particle injection toward the center of the plume, which results in the most efficient particle heating in the free jet (Ref 27). Consequently, the footprint illustrated in Fig. 15 shows less overspray particles.

\section{Conclusions and Outlook}

The aim of this study was to develop a novel method for verifying the measured in-flight particle properties by estimating the particle mass flow rate (PMFR) in the free jet. To this end, the entire free jet cross section was divided into several non-overlapping focal planes. To derive the PMFR, the size and velocity of the in-flight particles at these focal planes were measured by optical particle diagnostics. The PMFR of the powder feeder was used as a reference to validate the determined PMFR in the free jet. The PMFR obtained directly at the outlet of the powder injection nozzle was then utilized to calibrate the measured PMFR in the free jet. Diagnostic experiments were carried out with both a single-cathode and a three-cathode plasma generator, as well as using two different feedstock powders. It must be pointed out that similar approaches in terms of measuring the PMFR in the free jet have not been reported in the literature so far.

The presented method is capable of estimating the PMFR in the free jet with a deviation of less than $5 \%$ relative to the PMFR of the powder feeder. Furthermore, the key benefit of the developed approach is that no rotationally symmetric particle flow has been assumed. This makes the determined PMFR distribution more precise. The results could be replicated with different feedstock powders, demonstrating the capability of the developed method. Different input power levels for the different plasma generators were used to investigate the possible effect of the gas flow and gas composition on PMFR. We did not observe different results in terms of the PMFR estimation. This indicates that the measured PMFR is independent of the plasma density and thus, the result is predominantly determined by the PMFR at the injection head exit.

The spatial PMFR distribution at the entire free jet, referred to as digital footprint, showed a good agreement with the height profile of the corresponding experimental footprints. The results exhibit a more accurate determination of the PMFR in the case of utilizing spherical feedstock powder with relatively large particles as well as deploying a three-cathode plasma gun. To capture also fine particles with a diameter $<5 \mu \mathrm{m}$, similar systems with a higher resolution are required. For example, a state-of-the- art high-speed camera could be used in combination with image analysis.

Moreover, a cloud of undeposited particles existing at the periphery of the digital footprints was observed. Future studies could investigate the properties of these particles to improve the understanding of particle behavior in the free jet. In addition, the introduced method provides a good starting point for determination of the deposition efficiency by estimating the PMFR near the substrate.

Acknowledgments Open Access funding provided by Projekt DEAL. This work was based on the DFG Project BO 1979/51-1 "Developing a method for in situ determination of the deposition efficiency in thermal spraying." The authors gratefully acknowledge the financial support of the German Research Foundation (DFG).

Open Access This article is licensed under a Creative Commons Attribution 4.0 International License, which permits use, sharing, adaptation, distribution and reproduction in any medium or format, as long as you give appropriate credit to the original author(s) and the source, provide a link to the Creative Commons licence, and indicate if changes were made. The images or other third party material in this article are included in the article's Creative Commons licence, unless indicated otherwise in a credit line to the material. If material is not included in the article's Creative Commons licence and your intended use is not permitted by statutory regulation or exceeds the permitted use, you will need to obtain permission directly from the copyright holder. To view a copy of this licence, visit http://creativecommons. org/licenses/by/4.0/.

\section{References}

1. F. Miranda, F. Caliari, A. Essiptchouk, and G. Pertraconi, Atmospheric Plasma Spray Processes: From Micro to Nanostructures, Atmospheric Pressure Plasma-From Diagnostics to Applications, A. Nikiforov and Z. Chen, Ed., IntechOpen, London, 2019,

2. M. Vardelle, A. Vardelle, P. Fauchais, K.-I. Li, B. Dussoubs, and N.J. Themelis, Controlling Particle Injection in Plasma Spraying, J. Therm. Spray Technol., 2001, 10(2), p 267-284

3. K. Bobzin, Oberfä̈chentechnik Für Den Maschinenbau, 1st ed., Wiley-VCH, Weinheim, 2013 (in German)

4. L. Chen, Processing, Microstructures and Properties of Thermal Barrier Coatings (TBCS) by Plasma Spraying (PS), Thermal Barrier Coatings, Elsevier, Amsterdam, 2011, p 132-160

5. K.E. Schneider, Thermal Spraying for Power Generation Components, Wiley-VCH, Weinheim, 2006

6. A. Vardelle, C. Moreau, J. Akedo, H. Ashrafizadeh, C.C. Berndt, J.O. Berghaus, M. Boulos, J. Brogan, A.C. Bourtsalas, A. Dolatabadi, M. Dorfman, T.J. Eden, P. Fauchais, G. Fisher, F. Gaertner, M. Gindrat, R. Henne, M. Hyland, E. Irissou, E.H. Jordan, K.A. Khor, A. Killinger, Y.-C. Lau, C.-J. Li, L. Li, J. Longtin, N. Markocsan, P.J. Masset, J. Matejicek, G. Mauer, A. McDonald, J. Mostaghimi, S. Sampath, G. Schiller, K. Shinoda, M.F. Smith, A.A. Syed, N.J. Themelis, F.-L. Toma, J.P. Trelles, R. Vassen, and P. Vuoristo, The 2016 Thermal Spray Roadmap, J. Therm. Spray Technol., 2016, 25(8), p 1376-1440

7. D. Wroblewski, G. Reimann, M. Tuttle, D. Radgowski, M. Cannamela, S.N. Basu, and M. Gevelber, Sensor Issues and Requirements for Developing Real-Time Control for Plasma Spray Deposition, J. Therm. Spray Technol., 2010, 19(4), p 723735 
8. P. Fauchais and M. Vardelle, Sensors in Spray Processes, $J$. Therm. Spray Technol., 2010, 19(4), p 668-694

9. M. Friis, C. Persson, and J. Wigren, Influence of Particle In-Flight Characteristics on the Microstructure of Atmospheric Plasma Sprayed Yttria Stabilized $\mathrm{ZrO}_{2}$, Surf. Coat. Technol., 2001, 141(2-3), p 115-127

10. M.P. Planche, R. Bolot, and C. Coddet, In-Flight Characteristics of Plasma Sprayed Alumina Particles: Measurements, Modeling, and Comparison, J. Therm. Spray Technol., 2003, 12(1), p 101111

11. L. Zhao, K. Bobzin, F. Ernst, and E. Lugscheider, Atmospheric Plasma Spraying of Thermal Barrier Coating Material $\mathrm{ZrO}_{2}-$ $7 \% \mathrm{Y}_{2} \mathrm{O}_{3}$ Using On-Line Particle Monitoring, Adv. Eng. Mater., 2006, 8(4), p 268-270

12. Z. Yin, S. Tao, X. Zhou, and C. Ding, Particle In-Flight Behavior and Its Influence on the Microstructure and Mechanical Properties of Plasma-Sprayed $\mathrm{Al}_{2} \mathrm{O}_{3}$ Coatings, J. Eur. Ceram. Soc., 2008, 28(6), p 1143-1148

13. G. Mauer, R. Vaßen, S. Zimmermann, T. Biermordt, M. Heinrich, J.-L. Marques, K. Landes, and J. Schein, Investigation and Comparison of In-Flight Particle Velocity During the PlasmaSpray Process as Measured by Laser Doppler Anemometry and DPV-2000, J. Therm. Spray Technol., 2013, 22(6), p 892-900

14. J.F. Bisson, B. Gauthier, and C. Moreau, Effect of Plasma Fluctuations on In-Flight Particle Parameters, J. Therm. Spray Technol., 2003, 12(1), p 38-43

15. K. Bobzin, M. Öte, J. Schein, and S. Zimmermann, Numerical Study on Plasma Jet and Particle Behavior in Multi-Arc Plasma Spraying, J. Therm. Spray Technol., 2017, 26(5), p 811-830

16. L. Zhao, K. Seemann, A. Fischer, and E. Lugscheider, Study on Atmospheric Plasma Spraying of $\mathrm{Al}_{2} \mathrm{O}_{3}$ Using On-Line Particle Monitoring, Surf. Coat. Technol., 2003, 168(2-3), p 186-190

17. T. Wiederkehr and H. Müller, Acquisition and Optimization of Three-Dimensional Spray Footprint Profiles for Coating Simulations, J. Therm. Spray Technol., 2013, 22(6), p 1044-1052
18. Y. Zheng and Q. Liu, Review of Techniques for the Mass Flow Rate Measurement of Pneumatically Conveyed Solids, Measurement, 2011, 44(4), p 589-604

19. D. Song, L. Peng, G. Lu, S. Yang, and Y. Yan, Digital Image Processing Based Mass Flow Rate Measurement of Gas/Solid Two-Phase Flow, J. Phys. Conf. Ser., 2009, 147, p 12048

20. K. Bobzin, N. Bagcivan, L. Zhao, I. Petkovic, J. Schein, K. HartzBehrend, S. Kirner, J.-L. Marqués, and G. Forster, Modelling and Diagnostics of Multiple Cathodes Plasma Torch System for Plasma Spraying, Front. Mech. Eng., 2011, 19(1), p 1

21. J.-L. Dorier, M. Gindrat, C. Hollenstein, A. Salito, M. Loch, and G. Barbezat, Time-Resolved Imaging of Anodic Arc Root Behavior During Fluctuations of a DC Plasma Spraying Torch, IEEE Trans. Plasma Sci., 2001, 29(3), p 494-501

22. J.L. Marqués, G. Forster, and J. Schein, Multi-Electrode Plasma Torches: Motivation for Development and Current State-of-theArt, TOPPJ, 2009, 2(1), p 89-98

23. J.R. Davis \& Associates and ASM International, Handbook of Thermal Spray Technology, ASM International, Cleveland, 2004

24. A. Vardelle, C. Moreau, N.J. Themelis, and C. Chazelas, A Perspective on Plasma Spray Technology, Plasma Chem. Plasma Process., 2015, 35(3), p 491-509

25. M. Öte, Understanding Multi-Arc Plasma Spraying, Dissertation, RWTH Aachen; Shaker Verlag GmbH.

26. K. Bobzin and M. Öte, Modeling Multi-Arc Spraying Systems, $J$. Therm. Spray Technol., 2016, 25(5), p 920-932

27. J. Schein, M. Richter, K.D. Landes, G. Forster, J. Zierhut, and M. Dzulko, Tomographic Investigation of Plasma Jets Produced by Multielectrode Plasma Torches, J. Therm. Spray Technol., 2008, 17(3), p 338-343

Publisher's Note Springer Nature remains neutral with regard to jurisdictional claims in published maps and institutional affiliations. 